\title{
THE VALIDITY AND CLINICAL UTILITY OF STRUCTURED DIAGNOSES OF ANTISOCIAL PERSONALITY DISORDER WITH FORENSIC PATIENTS
}

\author{
Luisa E. Marin-Avellan, PhD, CPsychol, \\ Gillian A. McGauley, FRCPsych, MD (Res), \\ Colin D. Campbell, PhD, MRCPsych, \\ and Peter Fonagy, PhD, FBA
}

\begin{abstract}
Current DSM-based instruments for personality disorders (PDs) limit the investigation of the course and outcome of treatment of these disorders. This study examined the validity of the Shedler-Westen Assessment Procedure-200 (SWAP-200) and the Structured Clinical Interview for DSM-IV Axis II PD (SCID-II) in a sample of forensic PD patients. Results based on 66 participants indicated that the SWAP-200 Q-factors reduced the frequency of diagnostic comorbidity of $\mathrm{PD}$ categories by half compared with the SCID-II. Only the SWAP-200's Antisocial PD category showed good convergent and discriminant validity with respect to other instruments describing aspects of PD. The validity of the cutoff score for severe antisocial PD was confirmed, and this category predicted severe incidents in the hospital at 1 year of follow-up. A violence risk scale was constructed, which differentiated violent and nonviolent offenders. The results support the validity of the SWAP-200 and its potential clinical utility with forensic PD patients.
\end{abstract}

The prevalence and complexity of personality disorders (PDs) are particularly high in forensic populations in both the criminal justice and health systems. In the UK, up to $73 \%$ of prisoners awaiting sentencing, $64 \%$ of sentenced males, and 50\% of female prisoners are estimated to meet criteria for the diagnosis of PD (Meltzer, 2008). For violent prisoners and PD

This article was accepted under the editorship of Robert F. Krueger and John Livesley.

From Centre for Medical and Healthcare Education, St George's University of London, London (L. E. M.-A., G. A. M.); Central and North West London NHS Foundation Trust (G. A. M.); Institute of Psychiatry, King's College, London (C. D. C.); and Research Department of Clinical, Educational and Health Psychology, University College London, and The Anna Freud Centre, London (P. F.).

This research was supported by a fellowship from the NHS National Programme in Forensic Mental Health Research and Development in the UK. We would also like to thank all the patients and staff who contributed to this study.

Address correspondence to Luisa Marin-Avellan, Clinique La Métairie, Avenue de Bois-Bougy, 1260 Nyon, Switzerland; E-mail: lavellan@lametairie.ch 
patients admitted to high-security hospitals, a high level of diagnostic comorbidity of PD is reported (average of 3.6 disorders), and diagnoses span all categories (Coid, 1992). Additionally, a large majority of PD prisoners and forensic patients have comorbid diagnoses of substance abuse, and many have a primary diagnosis of mental illness (Blackburn \& Coid, 1999; Blackburn, Logan, Donnelly, \& Renwick, 2003). The complex psychopathology of this population presents clinicians with particular challenges with respect to accurately differentiating Axis I and Axis II symptomatology and with the validity and clinical utility of PD diagnoses (Clark, 2007; Clark, Livesley, \& Morey, 1997; Krueger, 2005).

An additional problem related to the issue of categorization of disorders is that systematic approaches to diagnosing PD based on the DSM have limitations of their own. For example, these instruments rely to a large extent on asking the patients direct questions about their personality. This procedure is of partial utility with PD patients because they are often characterized by a limited capacity for introspection (Fonagy, 1998; Perry, 1992).

In the domain of forensic psychiatry specifically, studies have shown that antisocial PD is a known risk factor for recidivism, particularly for violent offending (Bonta, Law, \& Hanson, 1998). However, the high prevalence of this disorder-in 50\%-60\% of prisoners (Meltzer, 2008; NICE, 2009) and in 37\%-60\% of patients in medium and high-security hospitals (Coid, Kathan, Gault, \& Jarman, 1999)—means that a categorical diagnosis without an indication of severity is of limited use for violence risk assessments in these populations. Additionally, the DSM's diagnostic criteria for antisocial PD have been criticized because of their reliance on criminological and behavioral indicators, which confound diagnosis and outcome in the prediction of violence (Robins, Tipp, \& Przybeck, 1991).

The limitations of these instruments may partially account for findings from forensic clinical practice studies indicating that clinicians rarely use standardized instruments, particularly semistructured interviews, for diagnosing PD (Duggan \& Gibbon, 2008; Milton, 2000).

This study reports on the validity of the SWAP-200 (Westen \& Shedler, 1999a) in a forensic population, examines whether the use of the SWAP200 addresses any of the main limitations of DSM-based instruments, and comments on any limitations of the SWAP-200. We suggest that particular features of the SWAP-200 may be useful in the assessment of forensic PD patients. The SWAP-200 helps clinicians structure their judgments to reach a diagnosis on the basis of all their clinical knowledge and inferences about the patients. This instrument may provide clinicians with a wider clinical data set on which to base their clinical judgment compared to the data set generated from patients' answers and behavior in the course of a semistructured interview. The SWAP-200 also requires clinicians to assess the presence of functional aspects of the personality, such as the capacity for insight, which is central to the diagnosis of PD, as well as dysfunctional features. The SWAP-200 may also help address the prob- 
lem of comorbidity in this population because it uses a prototype matching approach to diagnoses based on the statistical correlation with $\mathrm{PD}$ prototypes. This procedure accepts the notion that many categories of $\mathrm{PD}$ might have aspects in common, but that it is the specific configuration of certain personality features that differentiates the prototypes and therefore the final diagnosis.

In contrast to these postulated advantages, researchers have raised concerns regarding the SWAP-200 (Widiger \& Boyd, 2009; Wood, Garb, Nezworski, \& Koren, 2007). Two of these concerns are, first, the fact that the SWAP-200 is based on a fixed distribution of personality features; this forces clinicians to make choices about the most salient personality features, which could artificially reduce diagnostic comorbidity. Second, the SWAP-200 can yield results in both the DSM categorization and an alternative categorization based on $\mathrm{Q}$-factors, but the latter has been questioned in terms of its coverage and validity.

Although the SWAP-200's validity with PD forensic patients has been supported by its developers and by independent researchers, the clinical populations in these studies appear to be at the less severe end of personality pathology and criminality (Bradley, Hilsenroth, Guarnaccia, \& Westen, 2007; Fowler \& Westen, 2010; Porcerelli, Cogan, \& Hibbard, 2004). The preliminary results of a small sample study $(n=30)$ of forensic PD patients detained in high security conducted by the current authors were promising in terms of the SWAP-200 offering a more parsimonious classification of DSM PD categories compared with the SCID-II and improving the convergent validity of the PD categories when both SWAP-200 and SCID-II were assessed against other instruments assessing interpersonal functioning and attachment (Marin-Avellan, McGauley, Campbell, \& Fonagy, 2005). It seems important to investigate whether the SWAP-200 Antisocial PD category can be useful in differentiating forensic psychiatric patients in a way that is both clinically meaningful and efficient at predicting violence, unlike the DSM diagnosis of Antisocial PD.

The main aim of the study was to investigate the concurrent validity of the SWAP-200 Q-factors with respect to the SCID-II. The study had two subsidiary aims. First, in the absence of a gold standard diagnostic measure for PD, the convergent validity of the SWAP-200 Q-factors and the SCID-II was compared in relation to other measures that assess aspects of personality functioning relevant to PD (e.g., interpersonal functioning and affect regulation). Second, the predictive validity of the SWAP-200 was investigated in relation to future inpatient violent behavior.

With respect to the main study aim, we anticipated that the level of agreement between the two instruments would be moderate to low and that the SWAP-200 would yield fewer instances of diagnostic comorbidity, because it incorporates prototypes into the system of categorization, as we explained here.

In relation to the second subsidiary aim, when clinicians need to make judgments concerning proneness to violence for risk assessment in the 
absence of adequate instruments (NICE, 2009), they mostly apply their intuition, based in part on judgments of the patient's personality, to provide risk assessments. As a substudy, we explored whether subsections of the SWAP-200, which tapped into clinicians' assessments of key specific personality features, could be used to differentiate the violent subgroup of patients, beyond the items describing overt violent behavior. These judgments may tap into clinicians' experience in predicting violence proneness and so prove useful in predicting violent behavior. In anticipation of this possibility, the predictive validity of the SWAP-200 was investigated in relation to violent behavior committed by the study group of patients prospectively over the subsequent year of their inpatient admission.

\section{METHOD}

\section{SAMPLE DESCRIPTION}

The participants comprised 66 sequentially admitted patients detained in a high-security hospital in England because they suffered from a mental disorder and posed a serious risk of harm to the public. Inclusion criteria were that the patient was age 18 years or over and had a PD according to $D S M-I V$ criteria, as indicated by the screening version of the SCID-II, which the patients completed during the selection stage. Exclusion criteria were poor proficiency in English, physical disability, an IQ below 70, or active symptoms of psychosis. The latter was assessed initially using unstructured clinical judgment and the psychiatric admission reports, and later using the expanded version of the Brief Psychiatric Rating Scale (BPRS-E; Ventura, Green, Shaner, \& Liberman, 1993).

In the substudy on violence risk prediction, the sample was divided into violent and nonviolent subgroups based on whether the patients had been convicted of at least one previous violent offense according to their criminal records. Offenses were categorized according to Taylor and Gunn's (1984) typology. Violent offenses included homicide, attempted murder, infanticide, grievous bodily harm, actual bodily harm, assault, making an affray, wounding, and threats of violence. The two subgroups are characterized in Table 1 . The patients in the violent group were older $(t=2.82$, $p \leq .01$ ), had significantly more criminal convictions of all kinds, and had spent a longer time in custodial sentences compared to the patients in the nonviolent group $(t=3.76, p \leq .001$ and $t=2.65, p \leq .02$, respectively). Although comorbid Axis I disorders were frequent across the sample, there were no statistically significant differences between the two subsamples.

\section{RESEARCH PROCEDURE}

After Local Research Ethical Approval had been granted, potential subjects were identified from sequential admissions to the hospital and written informed consent was obtained. Self-report interview schedules were 
Table 1: Sample Characteristics

\begin{tabular}{lcc}
\hline Variables & $\begin{array}{c}\text { Violent Group } \\
(\boldsymbol{n}=\mathbf{3 7})\end{array}$ & $\begin{array}{c}\text { Nonviolent Group } \\
(\boldsymbol{n}=\mathbf{2 9})\end{array}$ \\
\hline Mean + Standard deviation (range) & 31 & 23 \\
Men & 6 & 6 \\
Women & $33.7 \pm 8.0(19-51)$ & $28.3 \pm 7.6(19-49)$ \\
Age & $89.4 \pm 12.8(70-126)$ & $96.0 \pm 15.5(71-135)$ \\
IQ & $15.4 \pm 20.8(1-94)$ & $2.4 \pm 3.0(0-12)$ \\
Number of previous convictions & $73.9 \pm 77.2(0-300)$ & $31.3 \pm 56.2(0-285)$ \\
Total time served in prison (months) & & $7(24)$ \\
Frequencies (\%) & $15(41)$ & $10(34)$ \\
Mood disorder & $20(54)$ & $14(48)$ \\
Schizophrenia* & $11(30)$ & $18(62)$ \\
Other psychoses* & $25(68)$ & $11(38)$ \\
Alcohol abuse & $17(46)$ & $18(62)$ \\
Alcohol dependence & $29(78)$ & $7(24)$ \\
Substance abuse & $17(46)$ & $12(41)$ \\
Substance dependence & $8(22)$ & \\
Anxiety disorders & & \\
\hline
\end{tabular}

*But currently free of active symptoms.

administered in two sittings within the same week. The recruited sample was followed up for a year at 3-month intervals. Follow-up data were collected using self-report instruments, violence records based on staff incidence forms, and psychiatric assessments at 3-month intervals. The clinical research team administering the measures comprised three psychiatrists and one psychologist.

\section{INSTRUMENTS}

Structured Clinical Interview for DSM-IV Axis II Personality Disorders (SCID-II). The SCID-II (First, Gibbon, Spitzer, Williams, \& Benjamin, 1997) is a semistructured interview that assesses the presence or absence of the 10 DSM-IV PDs and the appendix research categories. Diagnosis is reached by the presence of at least the minimum predetermined number of criteria for each of the categories. The SCID-II has been shown to be reliable (Maffei et al., 1997), but convergent validity with other PD instruments and procedures remains controversial (O’Boyle \& Self, 1990). The raters read the patients' psychiatric admission reports and medical notes prior to administering the SCID-II. The main raters were two psychiatrists who had 16 and 5 years of clinical experience. The psychologist on the research team, who 2 years later participated in the rating of the SWAP-200, also rated $20 \%$ of the SCID-II cases. She had 5 years of clinical experience at the time of the rating. The senior psychiatrist was trained to administer and rate the SCID-II and trained the other clinical researchers. Reliability computed on the double rating of 10 participants was high (average Kappa values across categories: 0.81; range: 0.13-1.00).

Shedler-Westen Assessment Procedure-200 (SWAP-200). The SWAP-200 (Westen \& Shedler, 1999a, 1999b) is a Q-sort instrument designed to quantify clinical judgment of personality pathology. The set of 200 person- 
ality-descriptive statements is ranked into eight categories by a clinician with a thorough knowledge of the patient, following a fixed distribution. This means that the clinician must place a predetermined number of items in each of the ranking piles in the following way: Half (100) of the items need to be placed in the nondescriptive Pile 0 , and only 12,10 and 8 items may be placed in Piles 5, 6, and 7, respectively, which contain the most descriptive features of the patients' personality. The intermediate piles contain the items that apply to the patient to a lesser extent. The resulting order of the items is correlated with diagnostic prototypes to ascertain the degree of correspondence with each diagnostic category. The correlation coefficients are then transformed into T-scores. The cutoff point for the diagnosis of PD is a score of 60 , and for marked features of PD, 55. SWAP-200 can yield results based on either prototypes of DSM categorization or on an alternative classification derived through $\mathrm{Q}$-analysis that contains 11 diagnostic categories or $\mathrm{Q}$-factors. The $\mathrm{Q}$-factors were the ones used in the current study, although the DSM scores were also computed in order to compare diagnostic comorbidity with the $\mathrm{Q}$-factors and with the SCID-II. The SWAP-200 has been shown to be reliable (Westen \& Shedler, 1999a), and the $\mathrm{Q}$-factors are reported to be a valid categorization of personality pathology (Westen \& Shedler, 1999b).

In the current study, the SWAP-200 was rated 2 years after the SCID-II on the basis of a standard set of clinical information about the patients comprising the audio recording and typed transcripts of the Adult Attachment Interview (AAI; George, Kaplan, \& Main, 1996) along with patients' admission psychiatric, psychological, and social work reports. The rating of this instrument does not require formal training. The raters comprised the psychologist who rated some of the SCID-II cases and one psychiatrist who had 5 years of clinical experience. The senior psychiatrist who rated the SCID-II was the third rater in the reliability study. Reliability computed on the rating of 10 participants with the senior psychiatrist and of 20 participants between the other two raters was high (average Pearson correlation coefficient across categories: 0.92; range: 0.72-0.96).

An attempt was made to create a scale based on SWAP-200 items that would characterize the violent offenders. In this part, the patients who had a lifetime diagnosis of schizophrenia were excluded because this diagnosis is also a known risk factor for violent recidivism. A group of items was selected for testing by clinical consensus in the research team and informed by the literature on violence and violence risk assessment. These items are listed in Table 3 in the Results section.

Brief Psychiatric Rating Scale-Expanded Version 4.0 (BPRS-E). The BPRS$\mathrm{E}$ (Ventura et al., 1993) is a 24-item semistructured interview for the rapid assessment of psychiatric symptomatology in research. It includes 25 scales. In the current study, interrater reliability computed on the rating of 10 participants was high (average Kappa values across categories: 0.80; range: 0.58-0.99). The following scales were selected for the analysis, based on their potential capacity to measure aspects of PD: Anxiety, Depression, 
Table 2. Associations Between SWAP-200 Q-Factors and SCID-II Results

\begin{tabular}{lcc}
\hline PD Categories & $\begin{array}{c}\text { Categorical } \\
\text { Diagnoses } \\
\text { (Kappa) }\end{array}$ & $\begin{array}{c}\text { Dimensional } \\
\text { Scores } \\
\text { (Pearson) }\end{array}$ \\
\hline Paranoid & cc & 0.22 \\
Schizoid & cc & $0.35^{* *}$ \\
Antisocial & $0.27^{*}$ & $0.50^{* *}$ \\
Borderline & $0.24^{*}$ & $0.37^{* *}$ \\
Histrionic & cc & 0.17 \\
Narcissistic & cc & $0.28^{*}$ \\
Avoidant & cc & 0.20 \\
Dependent & cc & $0.26^{*}$ \\
Obsessive & cc & $0.31^{*}$ \\
Passive-Aggressive & 0.23 & $0.26^{*}$ \\
Depressive & cc & 0.14 \\
\hline
\end{tabular}

$* p \leq .05 ; * * \leq .01 ; \mathrm{cc}=$ cannot calculate because diagnosis is absent or its base rate is below $5 \%$.

Suicidality, Guilt, Hostility, Suspiciousness, and Unusual Thought Content (because of its possible link with paranoid PD).

Inventory of Personality Organization (IPO). The IPO (Clarkin, Foelsch, \& Kernberg, 1995) is a 193-item self-report questionnaire that assesses psychodynamic constructs of personality organization based on Otto Kernberg's theory of normal and pathological personality. It includes three primary clinical scales of Identity Diffusion, Primitive Psychological Defenses, and Reality Testing, and a scale of Moral Values.

Revised Gudjonsson Blame Attribution Inventory (BAI). The revised BAI (Gudjonsson \& Singh, 1989) is a self-report questionnaire with 45 true/ false items measuring attribution of blame for a specific offense. It consists of three independent attribution scales: External, Mental Element, and Guilt.

Inpatient Antisocial Behaviour Scale (IABS). The IABS is a behavioral outcome measure relating to antisocial behavior that was purposely developed for this study and contains two subscales: Incidents and Seclusions. "Incidents" was operationalized into a 5-point scale for incidents and transgressions, and "Seclusions" is based on a 7-point scale of data on seclusions, transfers to prison, and untoward incidents and transgressions. This scale was rated by the senior psychiatrist and a graduate medical student who was naïve to the study aims and was not involved in the data collection. Good interrater reliability was found for all the participants at each of the follow-up points ( $r=0.94$ for Seclusions and $r=1.0$ for Incidents).

\section{STATISTICAL APPROACH}

The data of the current study were analyzed using SPSS version 15.0. To test the level of agreement between the SWAP-200 and the SCID-II, the Kappa statistic was used for categorical diagnoses of PD. In addition, to 
circumvent the insensitivity of categorical diagnoses and recognizing the likely dimensionality of PD classification (Shedler et al., 2010), we also computed SCID-II dimensional scores based on the number of criteria endorsed per diagnostic category. We then computed Pearson correlation coefficients between the dimensional SCID-II scores and the SWAP-200 DSM and Qfactor scores. Nonparametric tests were used to compare the number of SWAP-200 Q-factor and SCID-II diagnoses per patient and the probability of each of the PD categories being diagnosed with the two instruments (Wilcoxon signed-rank test and McNemar test, respectively). The remaining analysis of SWAP-200 convergent validity with the other instruments was carried out using Pearson correlation coefficients only on Q-factor scores where average scores above 50 suggested significant representation of the personality prototype in the sample. To further explore the SWAP-200 items that could be indicators of personality types describing violent individuals, multiple $t$ tests with Bonferroni significance adjustments were used to identify items with the greatest chance of discriminating patients with violent and nonviolent histories (patients who had a lifetime diagnosis of schizophrenia were excluded, as explained previously). The final aim regarding the predictive validity of the SWAP-200 was tested using receiver operating characteristic (ROC) analysis between the SWAP-200 Q-factor scores and the IABS. For this purpose, the IABS Seclusions scale was recoded as a binary variable with a cutoff point of 3 indicating "severe incidents."

\section{RESULTS}

\section{DESCRIPTIVE RESULTS OF THE SWAP-200 AND THE SCID-II}

The mean number of PD diagnoses per person on the SCID-II was 2.98 (SD: 1.58; range: 1-7), compared with 1.42 (SD: 0.80; range: 0-3) yielded by the SWAP-200 $\mathrm{Q}$-factors diagnoses. Although the study focused on the Q-factors classification, in this part of the analysis we also examined the SWAP-200 DSM diagnoses to try to determine whether the decrease in diagnostic comorbidity was due only to the use of the fixed distribution of the SWAP-200 (because the scoring method is the same for both the DSM and the $\mathrm{Q}$-factors) or to the type of categorization. The number of SWAP200 DSM diagnoses was higher than with the $\mathrm{Q}$-factors, but still lower than with the SCID-II ( $M=2.26$, SD: 1.35 ; range: $0-6)$. The difference between the frequency of SCID-II and SWAP-200 comorbidities was statistically significant on the Wilcoxon signed-rank test for both SWAP-200 DSM diagnoses $(z=2.75 ; p=.006)$ and for $\mathrm{Q}$-factor diagnoses $(z=5.48 ; p=$ $.001)$.

As Figure 1 clearly shows, in this sample, diagnostic criteria were met more often on the SCID-II for a range of categories compared with the SWAP-200 factors. This was significant on the McNemar test for Paranoid $(p<.001)$, Borderline/Emotional Dysregulation $(p<.001)$, Narcissistic $(p<.002)$, Avoidant $(p<.002)$, and Depressive $(p<.002)$ PDs. However, 


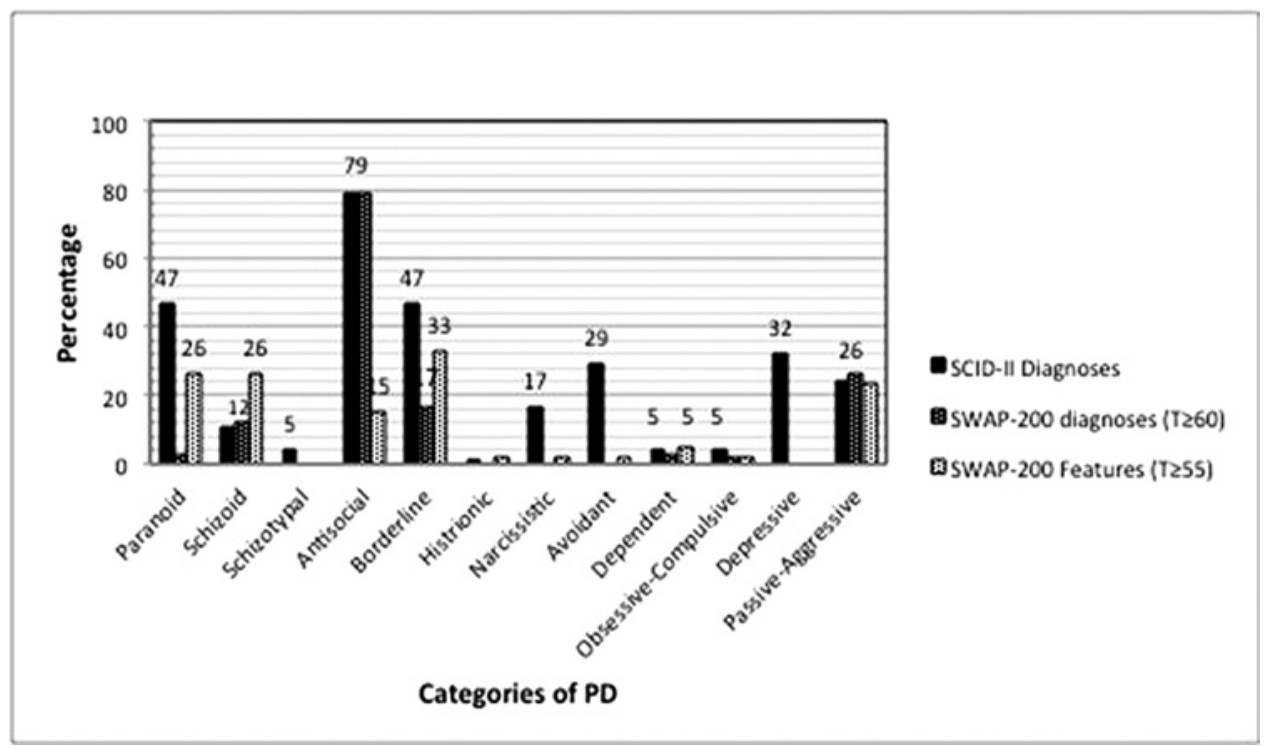

FIGURE 1. Diagnoses of PD based on SCID-II and SWAP-200 Q-factors.

when individuals with 'PD features' were also considered in the comparison, the number of Narcissistic $(p<.01)$ and Avoidant $(p<.001)$ diagnoses on SCID-II remained significantly higher, Paranoid and Borderline/Emotional Dysregulation were now equivalent, and there were significantly more SWAP-200 diagnoses of Antisocial $(p<.006)$ and Passive-Aggressive/Hostile Externalizing $(p<.003)$ PDs.

\section{CONCURRENT VALIDITY}

In relation to the SWAP-200's concurrent validity with respect to the SCIDII, the low base rate of several categories allowed the statistical comparison of only Paranoid, Antisocial, Borderline, Schizoid and Passive-Aggressive PD. Table 2 indicates that modest agreement was found for Antisocial PD and a significant but lower level of agreement was also found for Borderline and Passive-Aggressive PD, which did not improve when dimensional scores were used.

Comparisons with criminological variables showed that Antisocial PD on both the SWAP-200 and the SCID-II was significantly associated with a history of violent and acquisitive offenses and longer time spent in custodial sentences. This is unsurprising considering that both instruments include an item regarding history of unlawful and criminal behavior. In relation to the discriminant validity of the SWAP-200 items with respect to violence, Table 3 shows that the majority of the SWAP-200 personality characteristics $(73 \%)$ that were expected to characterize the violent offenders did so. However, possibly due to the high number of SWAP-200 items contained in the scale (i.e., 17, excluding the first two), the experi- 
Table 3. Effect Sizes of the SWAP-200 Items Differentiating Previously Violent $(n=29)$ From Nonviolent $(n=25)$ Nonschizophrenic Patients

\begin{tabular}{|c|c|c|}
\hline $\begin{array}{l}\text { Item } \\
\text { No. }\end{array}$ & Statement & d \\
\hline \multicolumn{3}{|c|}{ SWAP-200 items characterizing violent offenders } \\
\hline 40 & Tends to engage in unlawful or criminal behavior. & 1.240 .000 \\
\hline 115 & Tends to break things or become physically assaultive when angry. & 0.980 .001 \\
\hline 113 & Appears to experience no remorse for harm or injury caused to others. & 0.810 .004 \\
\hline 116 & $\begin{array}{l}\text { Tends to see own unacceptable feelings or impulses in other people instead } \\
\text { of in him/herself. }\end{array}$ & $0.790 .002 *$ \\
\hline & $\begin{array}{l}\text { Tends to blame others for own failures or shortcomings; tends to believe } \\
\text { his/her problems are caused by external factors. }\end{array}$ & 0.740 .005 \\
\hline 112 & $\begin{array}{l}\text { Tends to be unconcerned with the consequences of his/her actions; ap- } \\
\text { pears to feel immune or invulnerable. }\end{array}$ & 0.710 .008 \\
\hline 20 & Tends to be deceitful; tends to lie or mislead. & 0.670 .009 \\
\hline 153 & $\begin{array}{l}\text { Interpersonal relationships tend to be unstable, chaotic, and rapidly } \\
\text { changing. }\end{array}$ & 0.670 .008 \\
\hline & $\begin{array}{l}\text { Takes advantage of others; is out for number one; has minimal investment } \\
\text { in moral values. }\end{array}$ & 0.620 .013 \\
\hline & show reckless disregard for the rights, property, or safety of oth- & 0.620 .017 \\
\hline 194 & herc'emetions & 0.590 .019 \\
\hline & & 0.540 .024 \\
\hline 161 & Tends to abuse illicit drugs. & 0.530 .03 \\
\hline 185 & xpress intense and inappropriate anger, out of proportion to the & 0.520 .038 \\
\hline 188 & Wor & 0.520 .033 \\
\hline 134 & Tends to act impulsively, without regard for consequences. & 0.50 .039 \\
\hline \multicolumn{3}{|c|}{$\begin{array}{l}\text { SWAP-200 Items that were not originally hypothesized to differentiate the } \\
\text { violent groups but did characterize them }\end{array}$} \\
\hline & & \multirow{2}{*}{$\begin{array}{l}0.690 .008 \\
0.560 .02\end{array}$} \\
\hline 122 & e chao & \\
\hline & mannerisms traditionally associated with own & 0.560 .019 \\
\hline \multicolumn{3}{|c|}{$\begin{array}{l}\text { SWAP-200 items that were originally hypothesized to differentiate the } \\
\text { violent groups that were not characteristic }\end{array}$} \\
\hline & $\begin{array}{l}\text { Manages to elicit in others feelings similar to those he or she is experienc- } \\
\text { ing (e.g., when angry, acts in such a way as to provoke anger in others; } \\
\text { when anxious, acts in such a way as to induce anxiety in others). }\end{array}$ & $0.49 \mathrm{n} / \mathrm{s}$ \\
\hline & $\begin{array}{l}\text { Seeks to dominate an important other (e.g., spouse, lover, family member) } \\
\text { through violence or intimidation. }\end{array}$ & $0.39 \mathrm{n} / \mathrm{s}$ \\
\hline & $\begin{array}{l}\text { Is quick to assume that others wish to harm or take advantage of him/her; } \\
\text { tends to perceive malevolent intentions in others' words and actions. }\end{array}$ & $0.38 \mathrm{n} / \mathrm{s}$ \\
\hline 16 & y or hostile (whether consciously or unconsciously). & $0.36 \mathrm{n} / \mathrm{s}$ \\
\hline 147 & Tenc & $0.19 \mathrm{n} / \mathrm{s}$ \\
\hline 39 & $\begin{array}{l}\text { Appears to gain pleasure or } \mathrm{s} \\
\text { toward others (whether cor }\end{array}$ & $0.08 \mathrm{n} / \mathrm{s}$ \\
\hline
\end{tabular}

$\mathrm{d}=$ Cohen's effect size, ranges: small $=$ up to 0.49 , medium $=0.5$ to 0.79 , large $=0.8$ and above; *significant $\mathrm{p}$ with Bonferroni correction of $\mathrm{p} \leq .003$.

ment-wise error was quite high, with 54\% probability of type I error, and only the item referring to the projection of feelings and impulses in others was confirmed with a corrected $p$ value of below 003 .

A scale was constructed with these items, excluding the first two in order to avoid circularity in the prediction of violence, because a history of engaging in criminal activities and of being violent when angry can be viewed as both a predictor of violence and the outcome variable itself. 
Table 4. Associations Between Antisocial PD in SWAP-200 and SCID-II, and BPRS-E, IPO, BAI Scores and Incidents and Seclusions, $n=66$

\begin{tabular}{lccc}
\hline Measures & $\begin{array}{c}\text { SWAP-200 } \\
\text { Antisocial } \\
\text { PD }\end{array}$ & $\begin{array}{c}\text { SCID-II } \\
\text { Antisocial } \\
\text { PD }\end{array}$ & $\begin{array}{c}\text { Difference } \\
\text { of } \mathbf{z} \\
\text { scores }\end{array}$ \\
\hline BPRS-E & & & \\
Hostility & $0.30^{*}$ & 0.06 & 1.4 \\
Guilt & $-0.26^{*}$ & -0.1 & -1.44 \\
IPO & & & \\
Moral Values & $0.32^{*}$ & 0.2 & 0.72 \\
BAI & $-0.35^{* *}$ & -0.01 & $-1.99^{*}$ \\
Guilt & $0.27^{*}$ & 0.06 & 1.22 \\
Externalization & & & \\
Incidents in the follow-up periods & 0.24 & -0.2 & $2.51^{* *}$ \\
4 months & 0.01 & -0.18 & 1.08 \\
8 months & 0.06 & -0.19 & 1.42 \\
12 months & & & \\
Seclusions in follow-up periods & $0.28^{*}$ & 0.05 & 1.33 \\
4 months & 0.23 & 0.04 & 1.09 \\
8 months & $0.29^{*}$ & 0.01 & 1.62 \\
\hline months & &
\end{tabular}

BPRS-E = Brief Psychiatric Rating Scale; IPO = Inventory of Personality Organisation; $\mathrm{BAI}=\mathrm{Blame}$ Attribution Inventory; Two-tail significance: ${ }^{*} p \leq .05$, ${ }^{* *} p \leq .01$.

Items were coded 1 if in the original ranking of the SWAP-200 items they occupied piles 5, 6, or 7 (indicating the most descriptive features in the personality). Results showed that a score of 8 and above in a scale with a possible total score of 17 differentiated violent individuals with a sensitivity of 0.81 and specificity of 0.71 .

As Table 4 shows, appropriate associations were found overall between the selected BPRS-E, IPO, and BAI scales, and SWAP-200 Antisocial PD. Following our expectations, this category was significantly associated with high scores in hostility and low scores in guilt, as measured by three of the instruments. Guilt and Hostility scores in the BPRS-E were in the low range of the scale for the categorical diagnosis of Antisocial PD (i.e., Tscores $\geq 60$ ), but were significantly lower for severe Antisocial PD (T-scores $\geq 70$ ), which in the case of Guilt means the complete absence of guilt ( $t=$ 2.59, $p \leq .02, d f=64$, for Hostility; and $t=-2.04, p \leq .05, d f=64$ for Guilt). There were no statistically significant associations between Antisocial PD, as assessed by the SCID-II, and the other scales and measures. However, overall the correlations obtained with the SWAP-200 were in the low range, and only the association with Guilt was significantly higher than with the SCID-II.

\section{PREDICTIVE VALIDITY}

Regarding the predictive validity of the two PD instruments with respect to inpatient violence, only the SWAP-200 Antisocial PD Q-factor was significantly associated with the number of seclusions during the follow-up pe- 
riod $(r=0.32, p \leq .05$, and $r=0.30, p \leq .05$, for 8 and 12 months, respectively). However, the level of association with the outcome measure was modest, and although the correlations obtained with the SCID-II were close to nil, the difference between the two instruments did not reach statistical significance. ROC analyses showed that the SWAP-200 Antisocial PD Qfactor was moderately predictive of severe inpatient incidents on the Antisocial Scoring Scale of Incidents, which condenses frequency and severity of incidents into binary scores (area under the curve [AUC] $=0.70, p=.049$; and $\mathrm{AUC}=0.74, p=.019$, for 8 and 12 months' follow-up, respectively).

\section{DISCUSSION}

The main aim of the study was to assess various aspects relating to the convergent and predictive validity of the SWAP-200 Q-factors, an alternative type of diagnostic instrument for PD, comparing it with the SCID-II, which is a well-established measure. In addition, the study evaluated whether the SWAP-200 can be used to inform clinical and risk assessments of PD forensic patients.

\section{REDUCED FREQUENCY OF DIAGNOSTIC COMORBIDITY OF PD WITH THE SWAP-200}

The study patients were a severely disturbed clinical population with a high prevalence of Axis I and Axis II disorders, particularly Antisocial PD, which challenged the discriminant validity of both the SWAP-200 and the SCID-II. Results with the SCID-II were consistent with previously reported findings with similar samples in terms of the high frequency of diagnostic comorbidity of Axis II disorders (Blackburn et al., 2003). However, the SWAP-200 Q-factors yielded half as many diagnoses as the SCID-II. It was important to consider the scores close to the threshold for diagnosis, because with a dimensional measure, small differences around the cutoff score can change the number of diagnoses obtained without making a clinically meaningful difference. The results showed that even at the subthreshold level for scoring features of PD on the SWAP-200 (i.e., five points below the threshold for diagnosis of full PD), half of the PD categories were either completely absent or present at very low frequency. As previous authors have suggested (Widiger \& Boyd, 2009; Wood et al., 2007), the SWAP-200's lower frequency of diagnostic comorbidity could be a direct consequence of its fixed distribution, because it forces clinicians to identify a small subset of personality descriptive features, which in turn increases the likelihood that patients will meet criteria for fewer categories of disorder. However, in the current study we also examined the SWAP200 results yielded by $D S M$ categorization (which is based on the same rating procedure as the $\mathrm{Q}$-factors) and observed that several patients were diagnosed with multiple categories of PD (up to six categories), suggesting that a forced distribution does not automatically rule out the possibility of 
high diagnostic comorbidity. The SCID-II diagnosed up to seven PD categories, but the difference lay in the average number of diagnoses in the sample, which was still significantly lower with the SWAP-200 DSM categories.

We were also concerned as to whether the $\mathrm{Q}$-factor categorization of disorders was valid, because authors have suggested that the categories are too narrow compared to DSM categorization, which may lead to some cases not being diagnosed with a PD. As we discuss here, the current study aimed to test the convergent and predictive validity specifically of the Antisocial PD $\mathrm{Q}$-factor, because Antisocial PD is the most common category of PD in forensic samples.

\section{SWAP-200 ANTISOCIAL PD SCORES AND MEASURES OF HOSTILITY AND GUILT}

As expected, the sample was characterized by the presence of Antisocial PD, and the SCID-II and SWAP-200 showed an equal number of significant associations with criminogenic variables. However, only the SWAP200 Antisocial PD Q-factor scores were modestly but significantly associated with measures of hostility and lack of remorse, which are central aspects in the clinical definition of the disorder (American Psychiatric Association, 1994). It is important to note that the Hostility scale of the BPRS-E includes both overt and covert manifestations of hostility, that is, behavioral as well as intrapsychic components. The study included the assessment of guilt from the perspective of both the clinical researchers and the patients, using three different instruments. All three sets of scores were associated with the scores in Antisocial PD on the SWAP-200 Q-factors, indicating that the higher the Antisocial PD scores, the less guilt patients rated themselves as experiencing or were perceived to have. This finding may provide a helpful clinical pointer, as a previous study has shown that lack of remorse is directly linked to both a higher risk of violent recidivism and negative treatment change (Fox \& Leicht, 2005). Despite these clear trends of associations with the SWAP-200, further confirmation is required specifically in relation to establishing its possible superiority with respect to the SCID-II, because the level of associations remained in the low range and only the correlation with the absence of Guilt was statistically better with the SWAP-200's Antisocial PD Q-factor than with its counterpart in the SCID-II.

\section{VALIDITY OF THE SEVERITY CUT-OFF SCORE IN THE ANTISOCIAL PD SCALE}

Determining the severity of PD is also a difficult task, particularly with PD forensic patients in high-security hospital settings, because this population tends to be homogeneous in terms of both the presence of Antisocial PD and the high frequency and/or severity of offending. Previous classifi- 
cations have relied on the number and clusters of PD categories for which the patients meet criteria to establish the severity of PD (Blackburn \& Coid, 1999; Tyrer \& Johnson, 1996). However, these classifications have limited clinical use for either planning treatment or measuring progress because of the static nature of categorical diagnoses. The reported results using the SWAP-200 dimensional scores support the cutoff point for severe Antisocial PD, showing that it is a meaningful indication of significantly higher levels of hostility and of lack of remorse in this patient group, compared with patients who have a diagnosis of Antisocial PD but whose scores do not reach the cutoff point for severe PD. These findings could aid clinicians working with forensic populations in terms of guiding and supporting their clinical decisions about management and treatment. Until now the SWAP-200 had been used only with less severe forensic populations (Porcerelli et al., 2004); however, the results of this study confirm the absence of a ceiling effect for Antisocial PD, suggesting that this scale has the capacity to measure severe forms of the disorder.

\section{A SWAP-200-BASED VIOLENCE RISK SCALE FOR FORENSIC PD PATIENTS}

Violence risk is central to the assessment of forensic patients. DSM criteria for Antisocial PD have been criticized for being based mainly on behavioral and criminological factors; therefore, the current study assessed the discriminant validity of the SWAP-200 Q-factors with respect to violence and the predictive validity of the Antisocial PD $\mathrm{Q}$-factor in particular.

Results on the SWAP-200 items selected by the research team as being clinically linked to violence showed that the group of patients who had a history of violent convictions was characterized by significantly higher scores on these items. These findings are of particular interest because the nonviolent patients in the sample were also offenders and the majority had also committed serious crimes. The scale that was piloted using the SWAP-200 items that characterized the violent group yielded promising results in terms of differentiating the violent group from the nonviolent group with good sensitivity and specificity. Although further studies are needed to establish the statistical significance of all the items, the results of this exploratory study suggest that the SWAP-200 items could be helpful, in conjunction with generic violence risk assessment instruments, in guiding risk assessments with forensic PD patients and tailoring treatment interventions. In addition, because our scale contains some personality features that do not directly refer to a previous history of violent and criminal behavior, it could be useful in research directed at identifying first-time violent offenders. This group of "future" offenders is difficult to identify because the best predictor of violence is a history of violence (Bonta et al., 1998). 


\section{PREDICTIVE VALIDITY OF SWAP-200 ANTISOCIAL PD}

This study also explored the power of the SWAP-200 Antisocial PD Qfactor to predict inpatient violence, given that one of the main clinical uses of this PD category is in the prediction of violent recidivism. The results indicated that individuals with high scores in this SWAP PD category tended to engage in incidents of severe violence at 8- and 12-month follow-up points. Although the predictive capacity of the SWAP-200 was only moderate, it is notable that other research on the prediction of inpatient violence with PD patients using purposely designed violence risk assessment instruments, such as the HistoricalClinical-Risk management-20 guide (HCR-20; Webster, Douglas, Eaves, \& Hart, 1997), also report moderate predictive power (de Vogel \& de Ruiter, 2006; Dernevik, Grann, \& Johansson, 2002). However, in generic risk assessment instruments, the diagnosis of PD is only a single risk factor among many; some factors either apply only to mentally ill patients, such as with the HCR-20, or comprise criminogenic variables, for example, the Level of Service Inventory (LSI-R; Bonta \& Wormith, 2007) and the Violence Risk Scale (VRS; Wong \& Gordon, 1999). The main advantage of using the SWAP-200 with predominantly PD forensic patients to inform treatment and management interventions is that it provides a global assessment of personality and how individual personality features interact to either increase or reduce the risk of violence.

\section{LIMITATIONS}

The findings of the current study need to be considered in the context of its four main limitations. First, the study sample was very small, particularly compared with studies on violence risk prediction. The results therefore indicate possible trends that need to be explored further with larger samples. Second, the study included only a limited number of scales that measure intrapsychic aspects of PD. To further explore the validity of the SWAP-200, other scales need to be used. Third, some overlap of raters occurred in the rating of the instruments, which, although minor, could have influenced the results (except those between the SWAP-200 and both the BPRS-E and the outcome measure where there was no rater overlap). However, we attempted to guard against these overlaps biasing the results by undertaking interrater reliability studies for all measures which used third raters who were blind to the results from the different measures. Fourth, although both the SCID-II and SWAP-200 raters had access to the patients' multidisciplinary files and read the admission psychiatric reports, a weakness of the study was in failing to standardize the range of available clinical information so that each set of raters had exactly the same amount of knowledge about the patients. On the one hand, we did not control the extent to which or the thoroughness with which the SCID- 
II raters read the available admission reports, whereas for the SWAP-200 raters this was compulsory. On the other hand, the SCID-II raters may have been advantaged by their personal contact with the patients during the interviews, which was not available to the majority of the SWAP-200 raters. Future studies need to be able to control for these differences in procedure in order to allow a fairer comparison of the two instruments.

\section{CONCLUSIONS AND FUTURE DIRECTIONS}

Experts have long commented on the limitations of diagnostic instruments for PD, particularly regarding their validity, yet these instruments continue to be used in research (Livesley, 2006). The current study showed that the SWAP-200 and the SCID-II appeared to be equally reliable in diagnosing PD, even though the SWAP-200 is not necessarily based on a semistructured interview and relies largely on clinical judgment. In addition, the SWAP-200 Q-factors yielded half the diagnostic comorbidity of the SCID-II while showing sensitivity to capture psychopathology, as indicated by the good convergent validity of Antisocial PD, the most prevalent PD category in forensic psychiatric samples. The moderate predictive validity of the Antisocial PD category and its clinically meaningful differentiation of severity according to specific personality features support the use of the SWAP-200 for informing treatment planning and monitoring progress with PD patients, in conjunction with other approaches to improve violence risk assessments. Future research with the SWAP-200 needs to further examine the validity of all the PD categories (because fewer may be sufficient to capture the full spectrum of psychopathology), as well as the longterm stability of the 200 items.

\section{REFERENCES}

American Psychiatric Association. (1994). Diagnostic and statistical manual of mental disorders (4th ed.). Washington, DC: Author.

Blackburn, R., \& Coid, J. (1999). Empirical clusters of DSM-III personality disorders in violent offenders. Journal of Personality Disorders, 13, 18-34.

Blackburn, R., Logan, C., Donnelly, J., \& Renwick, S. (2003). Personality disorders, psychopathy and other mental disorders: Co-morbidity among patients at English and Scottish high security hospitals. Journal of Forensic Psychiatry and Psychology, 14, 111137.

Bonta, J., Law, M., \& Hanson, K. (1998). The prediction of criminal and violent re- cidivism among mentally disordered offenders: A meta-analysis. Psychological Bulletin, 123, 123-142.

Bonta, J., \& Wormith, S. (2007). Risk and need assessment. In G. McIvor \& P. Raynolds (Eds.), Developments in social work with offenders (pp. 131-152). London, UK: Jessica Kingsley Publishers.

Bradley, R., Hilsenroth, M., Guarnaccia, C., \& Westen, D. (2007). Relationship between clinician assessment and selfassessment of personality disorders using the SWAP-200 and PAI. Psychological Assessment, 19, 225-229.

Clark, L. A. (2007). Assessment and diagnosis of personality disorder: Perennial issues and an emerging reconceptual- 
ization. Annual Review of Psychology, 58, 227-257.

Clark, L. A., Livesley, W. J., \& Morey, L. (1997). Personality disorder assessment: The challenge of construct validity. Journal of Personality Disorders, 11, 205-231.

Clarkin, J. F., Foelsch, P. A., \& Kernberg, O. F. (1995). Manual for the Inventory Personality Organization (IPO) (draft) New York, NY: Department of Psychiatry, Cornell University Medical College.

Coid, J. (1992). DSM-III diagnosis in criminal psychopaths: A way forward. Criminal Behaviour and Mental Health, 2, 7894.

Coid, J., Kathan, N., Gault, S., \& Jarman, B. (1999). Patients with personality disorder admitted to secure forensic psychiatry services. British Journal of Psychiatry, 175, 528-536.

de Vogel, V., \& de Ruiter, C. (2006). Structured professional judgement of violence risk in forensic clinical practice: A prospective study into the predictive validity of the Dutch HCR-20. Psychology, Crime and Law, 12, 321-336.

Dernevik, M., Grann, M., \& Johansson, S. (2002). Violent behaviour in forensic psychiatric patients: Risk assessment and different risk-management levels using the HCR-20. Psychology, Crime and Law, 8, 93-111.

Duggan, C., \& S. Gibbon. (2008). Practical assessment of personality disorder. Psychiatry 7, 99-101.

First, M., Gibbon, M., Spitzer, R., Williams, J., \& Benjamin, L. (1997). Structured Clinical Interview for DSM-IV Axis II Disorders (SCID-II). Washington, DC: American Psychiatric Press.

Fonagy, P. (1998). An attachment theory approach to treatment of the difficult patient. Bulletin of the Menninger Clinic, 62, 147-169.

Fowler, K. A., \& Westen, D. (2010). Subtyping male perpetrators of intimate partner violence. Journal of Interpersonal Violence, 26, 607-639.

Fox, S., \& Leicht, S. (2005). The association between the offender-victim relationship, severity of offence and attribution of blame in mentally disordered offenders. Psychology, Crime \& Law, 11, 255-264.

George, C., Kaplan, N., \& Main, M. (1996).
Adult Attachment Interview Protocol (3rd ed.). Unpublished manuscript, University of California at Berkeley.

Gudjonsson, G. H., \& Singh, K. K. (1989). The Revised Gudjonsson Blame Attribution Inventory. Personality and Individual Differences, 10, 67-70.

Krueger, R. F. (2005). Continuity of axes I and II: Toward a unified model of personality, personality disorders, and clinical disorders. Journal of Personality Disorders, 19, 233-261.

Livesley, W. J. (2006). A framework for integrating dimensional and categorical classifications of personality disorders. Journal of Personality Disorders, 2, 199-224.

Maffei, C., Fossati, A., Agostoni, I., Barraco, A. Bagnato, M., Deborah, D.,... Petrachi, M. (1997). Interrater reliability and internal consistency of the Structured Clinical Interview for DSM-IV Axis II Personality Disorders (SCID-II), Version 2.0. Journal of Personality Disorders, 11, 279-284.

Marin-Avellan, L., McGauley, G., Campbell, C., \& Fonagy, P. (2005). Using the SWAP-200 in a personality-disordered forensic population: Is it valid, reliable and useful? Journal of Criminal Behaviour and Mental Health, 15, 28-45.

Meltzer, H. (2008). State-of-science review: SR-B5. The mental ill-health of prisoners. London, UK: Foresight Mental Capital and Wellbeing Project, The Government Office for Science. Retrieved from www.bis.gov.uk/assets/ foresight/docs/mental-capital/sr-b5_ mcw.pdf

Milton, J. (2000). A postal survey of assessment procedures for personality disorder in forensic settings. Psychiatric Bulletin, 24, 254-257.

NICE. (2009). Antisocial Personality Disorder: Treatment, management and prevention-NICE Clinical Guideline 77. London, UK: National Institute for Health and Clinical Excellence.

O’Boyle, M., \& Self, D. (1990). A comparison of two interviews for DSM-III-R personality disorders. Psychiatry Research, $32,85-92$.

Perry, C. (1992). Problems and considerations in the valid assessment of personality disorders. American Journal of Psychiatry, 149, 1645-1653.

Porcerelli, J. H., Cogan, R., \& Hibbard, S. 
(2004). Personality characteristics of partner violent men: A Q-sort approach. Journal of Personality Disorders 18, 151-162.

Robins, L. N., Tipp, J., \& Przybeck, T. (1991). Antisocial personality. New York, NY: Free Press.

Shedler, J., Beck, A., Fonagy, P., Gabbard, G. O., Gunderson, J., Kernberg, O., . . Westen, D. (2010). Personality disorders in DSM-5. American Journal of Psychiatry, 167, 1026-1028.

Taylor, P. J., \& Gunn, J. (1984). Violence and psychosis. British Journal of Psychiatry, 288, 1945-1949.

Tyrer, P., \& Johnson, T. (1996). Establishing the severity of personality disorder. American Journal of Psychiatry, 153, 1593-1597.

Ventura, J., Green, M. F., Shaner, A., \& Liberman, R. P. (1993). Training and quality assurance with the Brief Psychiatric Rating Scale: "The drift busters." International Journal of Methods in Psychiatric Research, 3, 221-244.

Webster, C. D., Douglas, K. S., Eaves, D., \& Hart, S. D. (1997). HCR-20 Assessing Risk for Violence, Version 2. Burnaby, Canada: Simon Fraser University.
Westen, D., \& Shedler, J. (1999a). Revising and assessing Axis II, part I: Developing a clinically and empirically valid assessment method. American Journal of Psychiatry, 156, 258-272.

Westen, D., \& Shedler, J. (1999b). Revising and assessing Axis II, part II: Toward an empirically based and clinically useful classification of personality disorders. American Journal of Psychiatry, 156, 273-285.

Widiger, T. A., \& Boyd, S. (2009). Personality disorders assessment instruments. In J. N. Butcher (Ed.), Oxford handbook of personality assessment (pp. 336363). New York, NY: Oxford University Press.

Wong, S., \& Gordon, A. (1999). Manual for the Violence Risk Scale. Saskatchewan, Canada: University of Saskatchewan.

Wood, J. M., Garb, H. N., Nezworski, M. T., \& Koren, D. (2007). The Shedler-Westen Assessment Procedure-200 as a basis for modifying DSM personality disorder categories. Journal of Abnormal Psychology, 116, 823-836. 